\title{
LA VISIÓN ETNOCÉNTRICADE LAS RELACIONES INTERNACIONALES Y SU REPERCUSIÓNEN LA APRECIACIÓN DE LOS DERECHOS HUMANOS
}

Armando Alvares GARCIA JÚNIOR*

\begin{abstract}
* Profesor de derecho internacional público, derecho del comercio internacional y sistemas jurídicos no occidentales (grado en derecho), estructura económica mundial, negocios internacionales, comercio exterior y dirección estratégica y política de la empresa - I (grado ADE) y negociación y marketing internacional (MBA-ADE) en la Universidad Internacional de la Rioja (UNIR), España. Director de trabajos de final de grado (Derecho y ADE). Miembro del Grupo de Investigación "CCSS-06 Justicia, Derecho y Globalización (GLOBALAW)" de la Universidad Internacional de la Rioja (UNIR).

armando.alvares@unir.net
\end{abstract}

Recebido em: 05/05/2015 - Aprovado em: 25/07/2016 - Disponibilizado em: 30/07/2016

RESUMEN: El artículo analiza la tendencia occidental de asociar la globalización a los derechos humanos, así como las limitaciones de esa perspectiva.

PALABRAS CLAVE: derechos humanos, etnocentrismo,Occidente.

\section{ETHNOCENTRIC VISION OF INTERNATIONAL RELATIONS AND THEIR IMPACT ON THE APPRECIATION OF HUMAN RIGHTS}

\begin{abstract}
The article analyzes the Western tendency to associate globalization human rights and the limitations of that perspective.
\end{abstract}

KEYWORDS:human rights, ethnocentrism, West.

\section{INTRODUCCIÓN}

La globalización no es un fenómeno que surgió después de la Segunda Guerra Mundial, sino que, dependiendo del criterio adoptado, hinca sus raíces en tres grandes impulsos históricos: a) la conquista, colonización e integración de América en el mercado mundial, b) la expansión colonial del siglo XIX resultante de la Revolución Industrial y c) el desarrollo y difusión cultural surgido después de la Segunda Guerra
Mundial e intensificado a partir de la década de los setenta hasta nuestro días por el avance tecnológico (Méndez Delgado \&LloretFeijóo, 2006) ${ }^{1}$. Como señala Temin $(2016)^{2}$, lo que se observa a lo largo y ancho de la historia, especialmente de la historia económica, es que por razones diversas (de nivel interno e internacional) la transnacionalización de las

\footnotetext{
${ }^{1}$ Méndez Delgado, Elier\&LloretFeijóo, María del Carmen (2006). Globalización: interrogantes y dimensiones. La Habana. Eumed.

${ }^{2}$ Temin, Peter (2016). Economic history and economic development: new economic history in retrospect and prospect. Springer Berlin Heidelberg.
} 
relaciones ha encontrado momentos de mayor o menor intensidad.

El hecho es que en Occidente, tal como señala $\operatorname{Baehr}(2016)^{3}$, existe una tendencia por parte de los juristas de asociar la globalización a la necesidad de expansión y consolidación de valores fundamentales de la civilización (pero de la civilización occidental): democracia, estado de derecho y derechos humanos, justamente las que orientan la política exterior de la Unión Europea.

Sin embargo, esta es una visión sesgada, a tal punto que en la teoría de las relaciones internacionales se afirma de modo unánime la existencia de una perspectiva etnocéntrica, europeísta en su inicio y occidental posteriormente, con su expansión.

\section{PROTECCIÓN DE LOSDERECHOS HUMANOSEN LOS SISTEMAS JURÍDICOS NO OCCIDENTALES}

La visión occidental de las relaciones internacionales - como medio difusor de sus grandes valores - predomina en la escena académica y diplomática mundial. De hecho, internacionalmente, los países afinaron posturas para concluir importantes tratados internacionales (como el Pacto Internacional de Derechos Civiles y Políticos y el Pacto Internacional de Derechos Económicos,

\footnotetext{
${ }^{3}$ Baehr, Peter (2016). Human rights: universality in practice. Springer, Berlín.
}

Sociales y Culturales, ambos de 1966). Paralelamente, en el ámbito doméstico, diversos países consagraron, en distintos niveles jerárquicos, la protección penal de derechos humanos como el derecho a la vida, a la libertad, a la integridad física, a la propiedad etc. Incluso, en diferentes partes del mundo, fueron establecidos, con mayor o menor éxito y eficacia, sistemas de protección de los Derechos Humanos, como por ejemplo, la Corte Interamericana de los Derechos Humanos, a fecha de hoy con 310 casos contenciosos, incluyendo las masacres de "El Mozote" en El Salvador y de "Santo Domingo" en Colombia (ambos de 2013), la "Masacre de Río Negro" en Guatemala (de 2012) y la "Masacre de Ituango", también en Colombia (de 2006).

No obstante, esa visión occidental de la globalización asociada a los derechos humanos no es compartida en todos los lugares. Un buen ejemplo se observa en la tradicional división del derecho penal en los países islámicos en las categoríashudud, qisasy taazir. Como señalan Ramzan,Akhter\&Rubab $(2015)^{4}$, la primera categoría expresa los crímenes más graves, recogidos en el Corán y la Sunna - las dos fuentes principales del derecho musulmán como el ateísmo, el agnosticismo, la apostasía, y la blasfemia. Los autores de eses

\footnotetext{
${ }^{4}$ Ramzan, Shazia, Akhter, Naseem\& Rubab, Ainee (2015). Punishment from Islamic Perspectives. FWU Journal of Social Sciences, 9(1), 53-61.
} 
crímenes son siempre perseguidos oficialmente, porque contrariarían directamente a Alá, razón que, bajo la perspectiva islámica, justificaría la adopción de sanciones tan severas como la amputación de miembros o la muerte (por decapitación, apedreamiento etc.). En sentido contrario, la perspectiva occidental consagra el derecho de libertad de culto o religiosa. No se condena a la muerte a nadie por ser ateo o agnóstico.

En el ámbito del derecho hindú, de base brahmánica, la situación tampoco se acerca a la visión quizá idílica del derecho occidental. Textos sagrados como el Rig $V e d a$, el Manusmritiy la costumbre (considerada jerárquicamente superior a cualquier ley) justifican, como señala Annoussamy $(2001)^{5}$, la división social en castas (Brahmanes ${ }^{6}$, Chatrías $^{7}$, Vaishias $^{8}$ y Shudrás $^{9}$ ) y la existencia de los Dalits $^{10}$, de las niñas devadasi ${ }^{11} \mathrm{y}$ de los Aghori ${ }^{12}$. Sanciones que varían en función de la casta, denegación de derechos a los Dalits, prostitución infantil legitimada por la

\footnotetext{
${ }^{5}$ Annoussamy, David. (2001). Le droit indien en marche. París:Société de Législation Comparée.

${ }^{6}$ Sacerdotes, maestros y recitadores de las Escrituras Sagradas.

${ }^{7}$ Nobles, políticos y militares.

${ }^{8}$ Agricultores, ganaderos, mercaderes y pequeños comerciantes.

${ }^{9}$ Campesinos y obreros.

${ }^{10}$ Descastados, personas que no tienen derecho a nada, ni a percibir una remuneración por su trabajo, por el simple hecho de haber nacido en ese colectivo.

${ }^{11}$ Niñas de entre 7 y 10 años de edad, consideradas "propiedad pública" y destinadas, en nombre de la tradición, a servir sexualmente a todas las personas del pueblo, sin derecho a rechazar a nadie).

${ }^{12}$ Canibales y necrófilos.
}

costumbre (Devadasi), admisibilidad del canibalismo y la necrofilia etc. no reflejan, naturalmente, la visión occidental de los derechos humanos.

En el caso asiático, se podría señalar tanto a China y su postura muchas veces represiva y violadora de los derechos humanos, que nadie desconoce, como a Japón, que a pesar de su actual modelo romano-germánico, permite a sus súbditos, como resultado de la combinación "budismoconfucionismo-sintoísmo", realizar una autocomposición extrajudicial en derecho penal (o sea, una solución consensual entre víctima y agresor), por aplicación de la denominada "reglas del giri" o "girininjo" (Vanoverbeke,Maesschalck\&Nelken,2014) ${ }^{13}$.

\section{CONCLUSIONES}

La globalización revela, cada vez más, valores occidentales, no necesariamente universales, al menos en este momento. En otras partes del mundo aun existe - y seguirá existiendo por muchos años - la percepción de que la escala de valores (que se refleja en términos de protección legal y sometimiento a la jurisdicción civil y penal) ha pasado por alto el desarrollo histórico y social de las sociedades no occidentales.

\footnotetext{
13 Vanoverbeke, Dimitri, Maesschalck, Jeroen\&Nelken,David (2014). The Changing Role of Law in Japan: Empirical Studies in Culture, Society and Policy Making. Edward Elgar Publishing.
} 


\section{REFERENCIAS BIBLIOGRÁFICAS}

Annoussamy, David. (2001). Le droitindien en marche. París: Société de

LégislationComparée.

Baehr, Peter (2016). Human rights:

universality in practice. Springer, Berlín.

Méndez Delgado, Elier\&LloretFeijóo, María del Carmen (2006). Globalización: interrogantes y dimensiones. La Habana. Eumed.

Ramzan, Shazia, Akhter, Naseem\&Rubab, Ainee (2015).

PunishmentfromIslamicPerspectives. $F W U$ Journal of Social Sciences, 9(1), 53-61.
Temin, Peter (2016). Economichistory and economicdevelopment: new economichistory in retrospect and prospect. SpringerBerlin Heidelberg.

Vanoverbeke, Dimitri, Maesschalck, Jeroen\&Nelken, David (2014). The Changing Role of Law in Japan: EmpiricalStudies in Culture, Society and PolicyMaking. Edward Elgar Publishing. 